\title{
Twenty-four-hour intraocular pressure patterns in a symptomatic patient after ab interno trabeculotomy surgery
}

This article was published in the following Dove Press journal:

Clinical Ophthalmology

7 November 2014

Number of times this article has been viewed

\author{
Kaweh Mansouri' \\ Felipe A Medeiros ${ }^{2}$ \\ Robert N Weinreb ${ }^{2}$ \\ 'Glaucoma Sector, Department \\ of Ophthalmology, Geneva University \\ Hospitals, Geneva, Switzerland; \\ ${ }^{2}$ Hamilton Glaucoma Center \\ and Department of Ophthalmology, \\ University of California, San Diego, \\ La Jolla, CA, USA
}

\begin{abstract}
We report the results of repeated ambulatory continuous 24-hour intraocular pressure (IOP) monitoring with a contact lens sensor (CLS) in a glaucoma patient with ocular pain after ab interno trabeculotomy (Trabectome ${ }^{\mathrm{TM}}$ ) surgery. Our findings show that a combined prostaglandin-pilocarpine treatment reduced nighttime IOP peaks and relieved the patient's symptoms.
\end{abstract}

Keywords: 24-hour, Trabectome contact lens sensor, prostaglandin-pilocarpine treatment

\section{Introduction}

$\mathrm{Ab}$ interno trabeculotomy with Trabectome $\mathrm{TM}^{\mathrm{TM}}$ is a generally safe surgical technique for glaucoma, in which the conventional outflow facility is increased through trabecular meshwork ablation. Recently, Ahuja et al ${ }^{1}$ reported a $4.6 \%$ prevalence of spontaneous delayed-onset hyphema after this procedure. They postulated "rapid ocular decompression after ocular compression during sleep" as a causative mechanism. The development of a contact lens sensor (CLS) enables monitoring of intraocular pressure (IOP) patterns for 24 hours, including during sleep. ${ }^{2,3}$ For the first time, continuous 24-hour IOP patterns after incisional glaucoma surgery are described.

\section{Case report}

A 59-year-old healthy female patient with advanced primary open-angle glaucoma underwent repeated 24-hour IOP monitoring with the CLS in the left eye (OS) (Figure 1). Goldmann applanation tonometry (GAT) was performed before placement and after removal of CLS. The patient had undergone selective laser trabeculoplasty (SLT) 14 months earlier, followed by Trabectome surgery in OS after three months. Despite postoperative IOPs in the low teens under a topical regimen with bimatoprost $0.01 \%$, her glaucoma was progressing. The patient complained of recurrent pain in OS occurring towards the end of the sleep period.

After a 1-month washout period, start and end GAT values were $13 \mathrm{mmHg}$ and $12 \mathrm{mmHg}$, respectively. The patient's diary showed that she went to bed at 23:20, woke up around 03:30 due to pain in OS, and remained awake mostly in the recumbent position for the rest of the night. She returned to the clinic and underwent a water drinking test (WDT): 1 L of water in 5 minutes at 08:30, after which the signal remained largely unchanged. The patient was re-started on bimatoprost $0.01 \%$.

A month later, the patient returned for a second monitoring session when start and end GAT values were $11 \mathrm{mmHg}$ and $12 \mathrm{mmHg}$, respectively. The patient instilled 


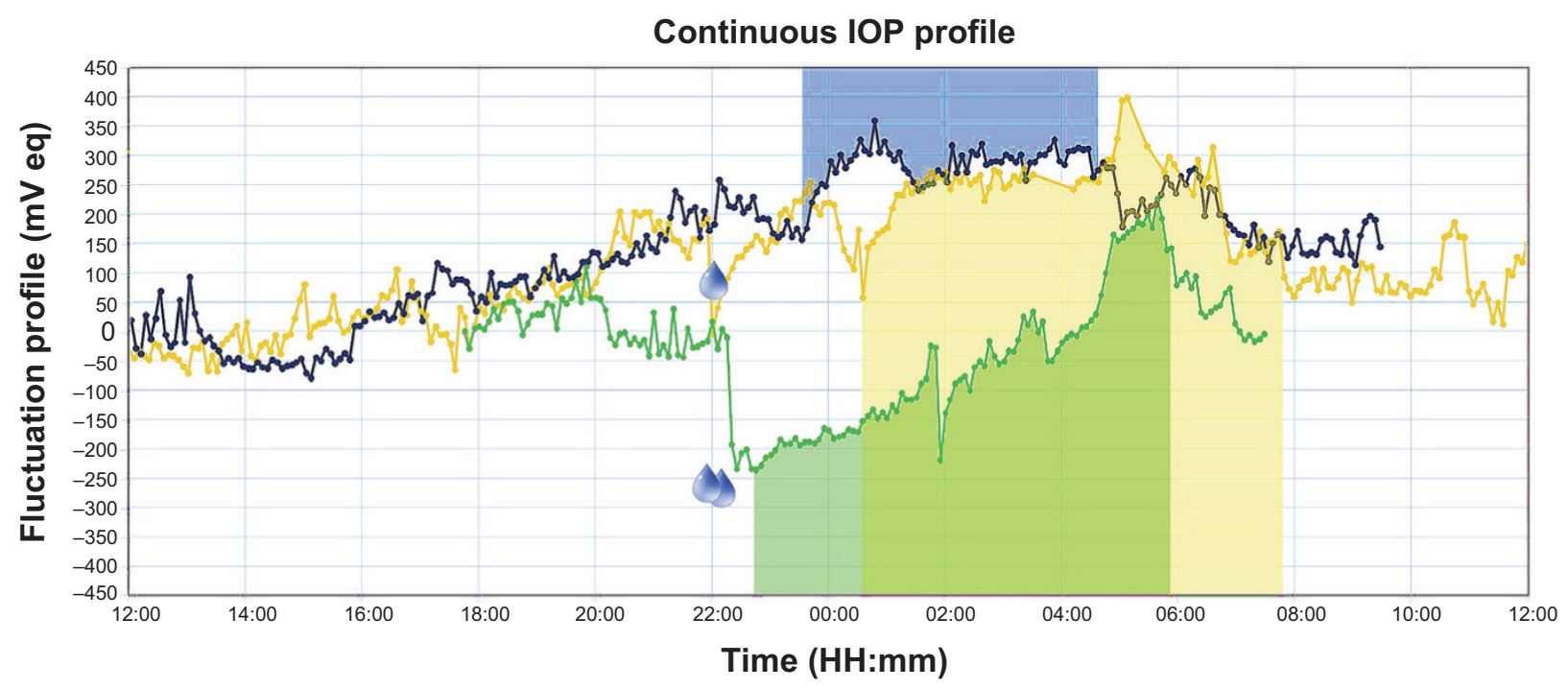

Figure I Results of 24-hour intraocular pressure monitoring in session I (blue line), session 2 (yellow line), and session 3 (green line). Notes: Drop signs indicate the time of drop instillation. Shaded areas correspond to periods of sleep in the recumbent body position. Abbreviations: IOP, intraocular pressure; $\mathrm{mV}$ eq, millivolt equivalent.

one drop of bimatoprost $0.01 \%$ at $21: 45$, after which a rapid signal drop was observed. She went to bed/sleep from 22:00 to $07: 00$. The next day, she reported persistence of symptoms in OS, corresponding with a peak signal around 05:00. WDT was performed at 10:10. The patient was started on once-daily pilocarpine $2 \%$ and maintained on bimatoprost.

The patient returned one month later and reported significant relief of pain in OS since the previous visit. Due to patient unavailability, IOP monitoring started at 17:30. Start and end GAT values were $12 \mathrm{mmHg}$ and $12 \mathrm{mmHg}$, respectively. At 22:15, the patient instilled bimatoprost drops, followed by pilocarpine at 22:45 and went to bed/sleep from 23:00 to 05:45. Following drug instillation, the signal dropped and remained below daytime values for the entire sleep period.

Twenty-four-hour IOP monitoring confirmed the presence of post-Trabectome IOP spikes associated with symptomatology of recurrent nighttime pain. The basis for the increased nocturnal IOP is unknown. One cannot preclude the possibility of a recurring nocturnal hyphema caused by reversal of the pressure gradient between IOP and episcleral venous pressure. ${ }^{1,4}$ Parekh et $\mathrm{al}^{5}$ observed intra-operative blood reflux during cataract extraction two years after Trabectome surgery, and hypothesized bleeding through focal neovascularization, similar to that found with Swan syndrome. Gonioscopy was performed after visits 2 and 3; small amounts of red blood cells could be seen only after visit 2. It is possible that a nocturnal microhyphema may have resorbed by the time of presentation. It is, however, also possible that the observed IOP spike would represent a delayed post-SLT rather than a post-Trabectome IOP spike.

\section{Conclusion}

We found that while instillation of bimatoprost had limited effect, the combination with pilocarpine seemed to blunt the nighttime IOP peaks. It is possible that the ciliary musclecontracting effect of cholinergic agents and the increased outflow facility might be the underlying mechanism for the observed IOP-lowering. ${ }^{6}$ Pilocarpine may further counteract hyphema-induced increased outflow resistance. To our knowledge, twenty-four-hour IOP-lowering effects of pilocarpine and its degree of additivity to prostaglandin analogs have not been previously reported, and merit further research.

\section{Disclosure}

Sensimed AG, Lausanne, Switzerland provided free material for this study. Kaweh Mansouri and Robert N Weinreb are consultants for Sensimed AG. The study was supported in part by an unrestricted grant provided by Research to Prevent Blindness (New York, NY, USA). Velux Foundation (Zürich, Switzerland) provided an unrestricted research grant to Kaweh Mansouri. The authors report no other conflicts of interest in this work.

\section{References}

1. Ahuja Y, Malihi M, Sit AJ. Delayed-onset symptomatic hyphema after ab interno trabeculotomy surgery. Am J Opthalmol. 2012; 154(3):476-480.

2. Mansouri K, Shaarawy T. Continuous intraocular pressure monitoring with a wireless ocular telemetry sensor: initial clinical experience in patients with open angle glaucoma. Br J Ophthalmol. 2011;95(5):627-629. 
3. Mansouri K, Medeiros FA, Tafreshi A, Weinreb RN. Continuous 24-hour monitoring of intraocular pressure patterns with a contact lens sensor: safety, tolerability, and reproducibility in patients with glaucoma. Arch Ophthalmol. 2012;130(12):1534-1539.

4. Ahuja Y, Malihi M, Sit AJ. Delayed-onset symptomatic hyphema after ab interno trabeculotomy surgery. Reply. Am J Ophthalmol. 2013; 155(4):779.
5. Parekh AS, Weinreb RN, Dorairaj SK. Delayed-onset symptomatic hyphema after ab interno trabeculotomy surgery. Am J Ophthalmol. 2013;155(4):778-779.

6. Bill A. Effects of atropine and pilocarpine on aqueous humour dynamics in cynomolgus monkeys (Macaca irus). Exp Eye Res. 1967; 6(2):120-125

\section{Publish your work in this journal}

Clinical Ophthalmology is an international, peer-reviewed journal covering all subspecialties within ophthalmology. Key topics include: Optometry; Visual science; Pharmacology and drug therapy in eye diseases; Basic Sciences; Primary and Secondary eye care; Patien Safety and Quality of Care Improvements. This journal is indexed on

Submit your manuscript here: http://www.dovepress.com/clinical-ophthalmology-journal

\section{Dovepress}

PubMed Central and CAS, and is the official journal of The Society of Clinical Ophthalmology (SCO). The manuscript management system is completely online and includes a very quick and fair peer-review system, which is all easy to use. Visit http://www.dovepress.com/ testimonials.php to read real quotes from published authors. 